\title{
Attitudes towards emergent autonomous robots in Austria and Germany
}

\author{
T. Gnambs (D)
}

\begin{abstract}
Autonomous robotic systems are an indispensable component of work in many industries that are on the brink of entering many other areas of people's lives such as transportation or healthcare. Because attitudes towards new technologies shape consumers' decision to adopt these innovations, the present study examines the public opinion toward emergent robotic systems in Austria and Germany. The results showed that, in general, attitudes seemed rather positive in both countries. However, for Austria a rather ambivalent picture emerged: although Austrians exhibited the largest adoption rate of robotic technologies in Europe, at the same time they evaluated robots most unfavorably as compared to other European countries. Thus, experiences with robots seemed to have intensified potential downsides of automation that resulted in more concerns regarding the widespread use of robots.
\end{abstract}

Keywords: robots; automation; attitudes; public opinion; cohort effect

\section{Einstellungen gegenüber Autonomen Robotern in Österreich und Deutschland.}

Autonome Roboter sind ein unverzichtbarer Teil der Arbeit in zahlreichen Industriezweigen und stehen kurz davor, auch andere Anwendungsfelder im Personenverkehr und Gesundheitswesen zu erobern. Da Einstellungen gegenüber neuen Technologien die Entscheidungen von Konsumenten beeinflussen, diese Neuerungen auch zu nutzen, untersucht die vorliegende Studie die öffentliche Meinung gegenüber neuen automatischen Systemen in Österreich und Deutschland. Die Ergebnisse zeigten im Allgemeinen eine eher positive Einstellung in beiden Ländern. Allerdings ergab sich in Österreich ein zwiespältiges Bild: Obwohl Österreicher die höchste Nutzungsrate von Robotertechnologien aufwiesen, hatten sie die negativsten Einstellungen. Es kann vermutet werden, dass zunehmende Erfahrungen mit Robotern auch die negativen Seiten von Automation verstärkten, was in skeptischere Einstellungen gegenüber einer verbreiteten Nutzung von Robotern mündet.

Schlüsse/wörter: Roboter; Automation; Einstellung; öffentliche Meinung; Kohorteneffekt

Received August 6, 2019, accepted September 26, 2019, published online October 21, 2019

(c) The Author(s) 2019

\section{Introduction}

For a long time, robots were reserved a place in the imaginative works of science-fiction writers and visionaries. However, recent decades faced an unprecedented technological burst with growing capabilities of autonomous systems that made robots emerge from mere fiction into the real world. Versatile autonomous robots can now perform a variety of complex tasks such as welding, assembling, packaging, cleaning and many more with no to very little human supervision. So far, most of these robots are used in the industrial sector; however, other fields are quickly catching up. Robots are expected to play a key role in the retail industry [1], tourism and hospitality [2], nursing and healthcare [3], and even future sex work [4]. For example, delivery services are already experimenting with drones and driverless cars [5], social robots are used to reduce loneliness among elderly [6], and virtual automated assistants such as Alexa or Google Home conquer the private homes [7]. Therefore, it is not surprising that robots have become a sizeable economic factor in many industries [8]. With about 106 robots per 10,000 employees, Europe has the highest workplace robot density in the world, even surpassing the United States (91 units) and Asia/Australia (75 units). Noteworthy, Austria and Germany are among the European countries with the largest share of robots in the automotive but also in the general industry [8].

The proliferation of robots at the workplace and the increasing diffusion of autonomous technical systems in other areas of people's lives have also led to worries about potential negative consequences of automation [9-12]. For example, one projection estimated that one fifth of the global labor force might be replaced with automated robotic systems by 2030 [11]. Others derived at less pessimistic conclusions but also suggested that an increased share of robots at the workplace will likely affect low-skilled workers, albeit having little effect on total employment rates [9]. As a result, public opinions in the United States about automation in everyday life [12] became rather wary. Although Americans also acknowledge some positive aspects of automation (e.g., the use of robots for dangerous work tasks), they are currently more likely to voice worries and concerns regarding the expected impact of emergent technologies. Thus, most Americans are rather hesitant to use automation technologies such as driverless cars or robot caregivers themselves. Recently, Gnambs and Appel [9] reported similar results for the European context by making use of representative samples from 27 countries of the European Union including over 80,000 respondents. On the one hand, they found that as of 2017 Europeans held, in general, a rather positive view of robots. Perceived benefits of automated technolo-

Electronic supplementary material The online version of this article (https://doi.org/10.1007/s00502-019-00742-3) contains supplementary material, which is available to authorized users.

Gnambs, Timo, Johannes Kepler University Linz, Altenbergerstr. 69, 4040 Linz, Austria and Leibniz Institute for Educational Trajectories, Wilhelmsplatz 3, 96047 Bamberg, Germany (E-mail: timo.gnambs@lifbi.de) 
Table 1. Sample compositions for Austria, Germany, and the EU-26

\begin{tabular}{llll}
\hline & Austria & Germany & EU-26 \\
\hline Sample size & 1001 & 1537 & 25363 \\
Percentage female & $52 \%$ & $51 \%$ & $52 \%$ \\
Mean age (SD) & 47.85 & 49.13 & 48.17 \\
& $(18.09)$ & $(18.83)$ & $(18.78)$ \\
Employment status: & & & \\
$\quad$ - Employed or self-employed & $57 \%$ & $51 \%$ & $48 \%$ \\
$\quad$ - Non-employed & $43 \%$ & $49 \%$ & $52 \%$ \\
Mean number of years in education (SD) & 5.39 & 5.61 & 5.68 \\
& $(2.49)$ & $(2.84)$ & $(2.86)$ \\
\hline
\end{tabular}

Note. Includes poststratification and population-size weights.

gies, for example, to help carry out daily tasks at home or take over jobs that are too dangerous for people, outweighed potential risks. On the other hand, when considering adopting emergent technologies themselves, Europeans were rather hesitant. Having robots perform medical operations on them, having robots to provide services and companionship to the elderly or infirm, or using a driverless car themselves were still rather unacceptable for most people. More importantly, longitudinal comparisons revealed that between 2012 and 2017 public opinions towards robots became increasingly more negative. Particularly, support for the use of robotic assistance at the workplace exhibited a marked decline within these five years. Unsurprisingly, attitudes towards robots were more negative among women and blue-collar workers with lower education that are likely to be most affected by increasing automation [10]. Gnambs and Appel [9] also found some differences between European countries. For example, attitudes towards robots were more positive in Northern as compared to Southern Europe. However, respective country differences became smaller over time resulting in more homogeneous attitudes in Europe. Detailed results on the public opinions in specific countries were not reported. Therefore, the present study extends these results to provide respective findings for Austria and Germany.

\section{Method}

\subsection{Sample and procedure}

The study draws on the Eurobarometer 87.1 [13] conducted in March 2017 that surveyed representative samples of European citizens aged 15 years or older. The sample sizes in each of the 28 countries of the European Union (EU) varied between 500 (Malta) and 1,537 (Germany) resulting in a total sample of $N=27,901$ respondents (55\% women). For Austria, 1,001 participants ( $52 \%$ women) with a mean age of 47.85 years $(S D=18.09)$ was available. About $57 \%$ of them were currently employed or self-employed, whereas the rest was either retired or otherwise non-employed. The sample compositions for Austria, Germany, and the remaining EU states are summarized in Table 1. All interviews were conducted face-to-face in the local national language.

\subsection{Instruments}

Before the interview, all respondents were introduced to the concept of autonomous robotic systems by presenting photos of a humanoid and a non-humanoid (industrial) robot. Then, they were informed that a robot is defined "as a machine which can assist humans in everyday tasks without constant guidance or instruction, e.g. as a kind of co-worker helping on the factory floor or as a robot cleaner, or in activities which may be dangerous for humans, like search and rescue in disasters. Robots can come in many shapes or sizes and some may be of human appearance. Traditional kitchen appliances, such as a blender or a coffee maker, are not considered as robots." [13, p. 17].

General attitudes towards robots were measured with three items asking about an overall evaluation of robots ("Generally speaking, do you have a very positive, fairly positive, fairly negative or very negative view of robots?") and rating the statements that (a) robots are a good thing for societies because they help people and (b) robots are necessary as they can do jobs that are too hard or too dangerous for people. Responses were given on four-point scales from "totally agree" (0) to "totally disagree" (3). The three items were reverse coded and summed up to create a composite score ranging from 0 to 9 . These scores had categorical composite reliabilities [14] of $\omega=.81, .75$, and.77 in Austria, Germany, and the EU-26, respectively.

Experiences with robots were assessed with three items asking whether the respondents had ever used or currently uses a robot (e.g., a robotic vacuum cleaner at home or an industrial robot at work) at home, at work, or elsewhere. The responses were pooled into an indicator for any robotic experience $(0=$ no experience, $1=$ any experience).

The perceived impact of digital technologies on (a) the economy, (b) the society, and (c) the respondent's quality of life was measured on four-point scales from "very positive" (0) to "very negative" (3). The three items were reversed coded and summed to create a composite score ranging from 0 to 9 . The respective reliabilities [14] in Austria, Germany, and the EU-26 were $\omega=.84, .79$, and.89, respectively.

\subsection{Statistical analyses}

Because some respondents had missing values on one or more variables (see supplement material), all analyses are based on 20 multiply imputed datasets that were created using classification and regression trees [15] in mice version 3.6.0 [16]. Moreover, post-stratification and population-size weights were used to derive parameter estimates that are representative for the European population (for more details see [13]). The results are reported in form of standardized mean differences as Cohen's $d(M=0, S D=1)$. Following Gnambs and Appel [9], Cohen's $d s$ of 0.20 and 0.30 are considered small and moderate effects, respectively. All analyses were performed in $R$ version 3.6.1 [17]. The data used for the analyses is available at https://doi.org/10.4232/1.12922, whereas the analysis code and results are provided at https://doi.org/10.17605/OSF.IO/RDCBN. A list of used abbreviations is given in the Appendix.

\section{Results}

\subsection{Attitudes towards emergent autonomous robots}

The average ratings of attitudes towards autonomous robotic systems in the 28 European countries were rather positive. The respective mean score was $5.78(S D=1.93)$ on a nine-point response scale. However, there were some variation between countries. Figure 1 (left panel) summarizes the respective ratings on a $z$-standardized scale that is centered at 0 , reflecting the average ratings across all European countries. These results highlight that some countries rated robots pronouncedly more positively whereas others held more negative views. In particular, Austrians $(M=5.44$, $S D=2.02$ ) were rather skeptical and had attitude scores of about $d=-0.18$ below the average rating of the EU-26 $(t=-3.80$, 

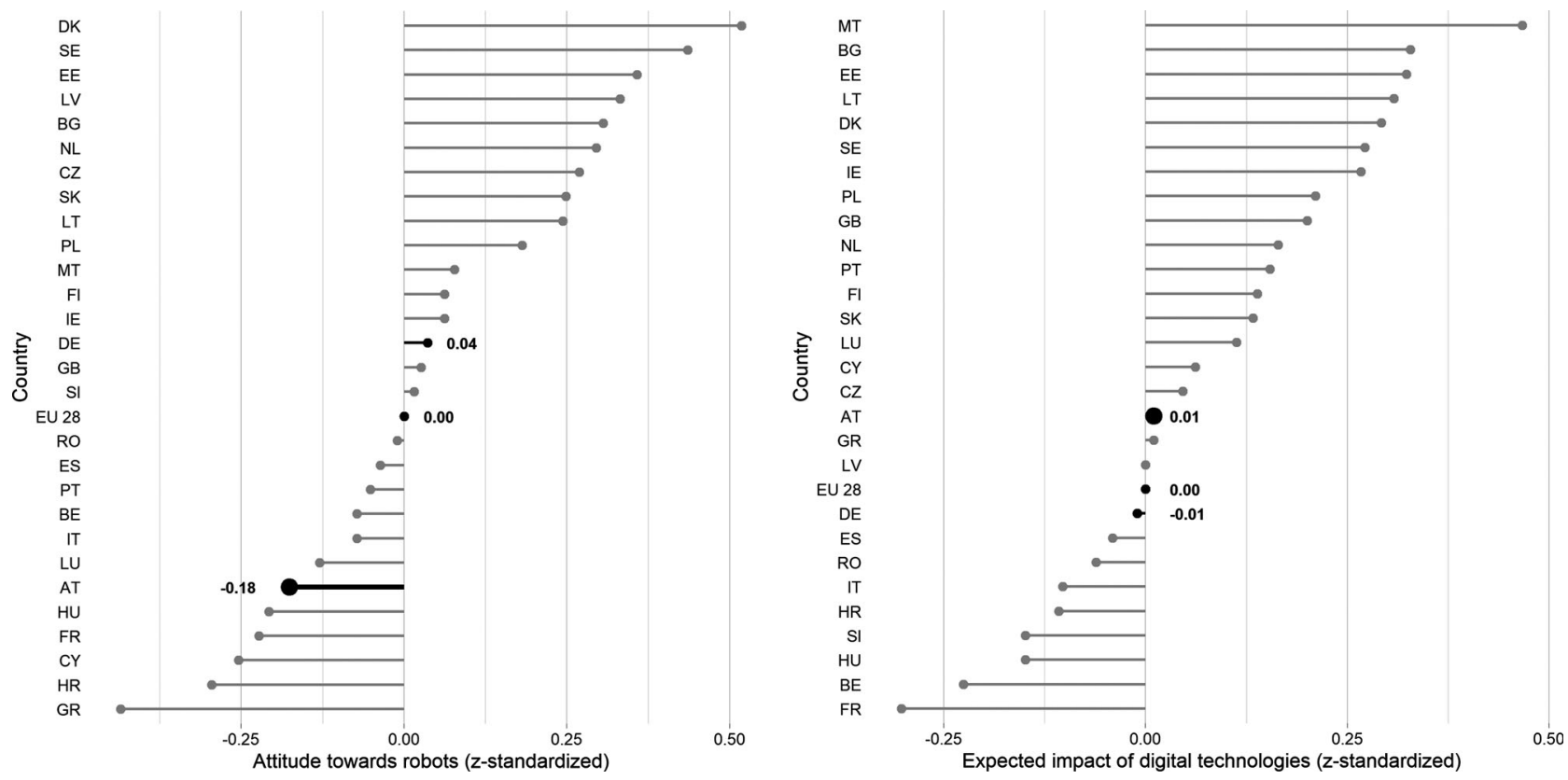

Fig. 1. Attitudes towards robots and expected impact of digital technologies in Europe. Ratings are given on a $z$-standardized scale that is centered at 0 , reflecting the average ratings across all European countries

$d f=16849, p<.001)$. The respective size of the observed difference might be considered small. However, given that explicit intervention programs designed to influence public opinions typically hover around $d=0.22[18]$ the observed difference in attitudes toward robots might be viewed substantial enough to warrant further investigation. Interestingly, the attitudes of German citizens $(M=5.85, S D=1.76)$ fell in line with the average rating among the EU-26 $(t=0.71, d f=4263, p=.477, d=0.01)$. Thus, despite the similar cultural and economic background of Austria and Germany the evaluations of autonomous robotic systems differed markedly.

\subsection{Attitudes towards digital technologies}

To evaluate whether Austrians might have more reservations regarding modern technologies in general, Fig. 1 (right panels) also summarizes the expected impact of digital technologies on respondent's lives. However, no substantial differences were found for Austria $(M=5.79, S D=1.83)$ or Germany $(M=5.75, S D=1.66)$. The respective effect sizes were close to 0 . In both countries, respective scores did not differ meaningfully from the average ratings in the other European countries $(t=0.01, d f=4909, p=.990, d=0.00$, and, $t=-1.89, d f=1114, p=.060, d=-0.03)$. Thus, the observed skeptical views on robotic systems in Austria cannot be accounted for by a more negative view on modern technologies in general.

\subsection{Cohort effects in attitudes towards robots}

Exploratory analyses revealed a cohort effect that partially explained the different attitude ratings for Austria (see Fig. 2). To this end, the attitude ratings were regressed on two dummy-coded indicators representing Austria or Germany (as compared to the remaining countries), the respondents' age (in years), the respective interactions, and several covariates (i.e., sex, years in education, job type). The respective results (see supplement material) showed that attitudes toward autonomous robots were rather similar for Germany and other European countries and did not vary substantially with the age of the respondents. In contrast, for Austria a pronounced

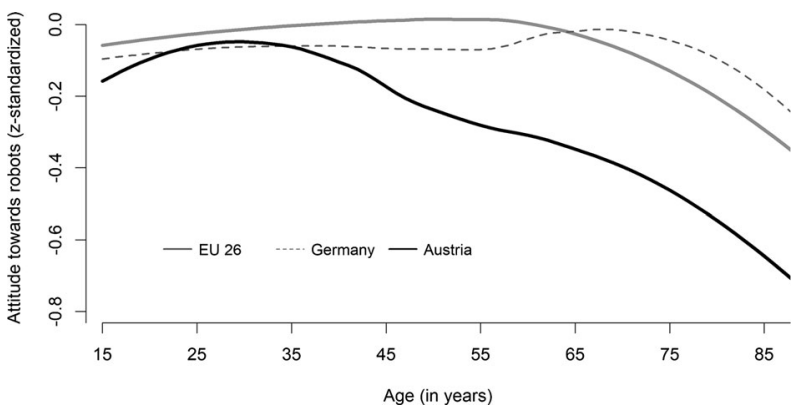

Fig. 2. Local regression for cohort differences in attitudes towards robots ( $z$-standardized) in Austria, Germany, and the EU-26 based on residualized attitude score controlling for sex and years in education

decline in attitude ratings beginning at about age 40 was observed (see Fig. 2). Particularly older age cohorts evaluated emergent automation significantly $(p<.05)$ more negatively as compared to younger cohorts. For example, mean attitudes did not differ substantially between Austria and the other European countries at age 30 year $(d=-0.06)$. However, respective differences gradually increased to $d=-0.18$ at age 50 years and $d=-0.31$ at age 70 years.

\subsection{Experiences with robots}

About $14 \%$ of the Europeans reported having used or are currently using a robot at home, the workplace, or elsewhere. Again, substantial variations between the different countries were observed (see Fig. 3). In Germany, significantly fewer respondents (11\%) indicated experience with robots as compared to the EU-26 $(t=-5.17$, $d f=17201, p<.001)$. In contrast, experiences with robots were more prevalent $(t=3.18, d f=26718, p=.001)$ among Austrian respondents (20\%). As expected, attitudes towards robots were systematically related to respondents' experiences with robots. Those who reported as having used a robot in the past also reported signifi- 


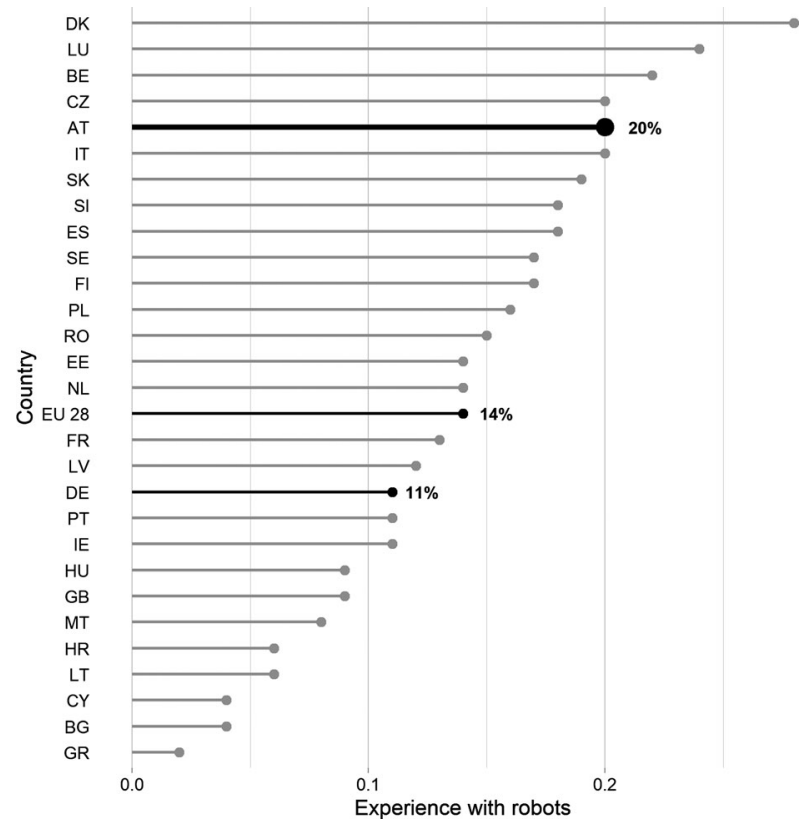

Fig. 3. Percentage of respondents reporting experiences with robots at home, work or elsewhere in Europe

cantly more positive attitudes toward automatic robots as compared to respondents without usage experience $(d=0.47, p<.001)$, even after controlling for socio-demographic differences (i.e., sex, age, years in education) between the two groups $(d=0.38, p<.001)$.

\section{Discussion}

Technological innovations in automation and artificial intelligence have irrevocably altered the way how people work, produce goods, or conduct their businesses. With the ongoing increase in computer power robotic assistance are likely to become a mass phenomenon and, thus, an integral part of everyday life. Social psychological theories and respective empirical evidence suggest that attitudes are an essential precursor of behavioral intentions and technology adoption [19] that determine the successful diffusion of a new technology in a society. Particularly, if consumers have a choice of whether to use new products (e.g., driverless cars) or not, negative attitudes might impede the diffusion of respective innovations. Therefore, monitoring the public opinion on important technological trends can help gauge the anticipated impact of emerging technologies.

The present study focused on attitudes towards autonomous robots in Austria and Germany. Extending prior research that summarized general trends in Europe [9], these analyses showed that, on average, attitudes were rather positive in both countries. However, particularly for Austria a rather ambivalent picture emerged. On the one hand, Austria is one of the countries in the European Union with the largest share of respondents reporting first-hand experience with robots either at work or at home. On the other hand, attitudes toward robots were among the most negative in Europe. Gnambs and Appel [9] speculated that this might be a result of approach-avoidance conflicts evoked by these technologies (cf. [20]). Automation can yield positive (e.g., assistance at work) as well as negative consequences (e.g., job loss). As long as these technologies represent hypothetical scenarios without actually being part of people's lives, approach tendencies are expected to dominate, thus, leading to rather positive evaluations of robots. In contrast, increasing experience with robots should instigate avoidance tendencies because also the negative consequences of the new technology become salient. Following this line of reasoning, it might be assumed that the observed differences in attitudes between Austria and the remaining European countries will diminish as soon as they have similar rates of experience with automatic robots. Another intriguing finding pertained to an age (or cohort) effect among Austrian respondents. Although there was a general trend of more negative attitudes towards robots among older respondents (see also [9]), this age effect was significantly stronger in Austria. Starting at about 40 years of age, Austrians evaluated robots substantially more negative as compared to respondents of the same age from other European countries. The reason behind this effect is still unclear. It might be speculated that this reflects a general trend towards more pessimistic world views in Austria (but see [21] for counterevidence) or peculiarities in the employment structure, thus, reflecting greater fears of job loss in Austria. Whether this effect replicates in upcoming years, is a task for future research

\subsection{Limitations}

Several limitations might impair the generalization of the reported findings. For one, the analyses relied on self-reports that might be distorted by various response styles [22]. Future research should strive to include objective measures of usage behaviors to get more detailed information on the use of robotic systems and contrast this data with the consumers' attitude ratings. Moreover, the cross-sectional design of the study does not allow causal conclusions. Therefore, it not clear in what way attitudes and technology adoption interact. Generally, there is a dearth of longitudinal research studying public opinions on emergent technologies. Systematic panel studies might elucidate processes within persons that determine attitudes and, more importantly, the adoption of new technologies.

\subsection{Conclusion}

The general evaluation of automated robotic systems in Austria and Germany is rather positive. However, comparative analyses revealed that Austrians evaluated automation more cautiously as compared to other European respondents. This might be partially explained by a larger share of users of robots in Austria leading to more realistic views of the benefits and disadvantages of automation. Moreover, cohort effects lead to more negative attitude ratings in Austria at middle and old age as compared to the rest of Europe.

\section{Acknowledgements}

Open access funding provided by Johannes Kepler University Linz.

Publisher's Note Springer Nature remains neutral with regard to jurisdictional claims in published maps and institutional affiliations.

Open Access This article is distributed under the terms of the Creative Commons Attribution 4.0 International License (http://creativecommons.org/ licenses/by/4.0/), which permits unrestricted use, distribution, and reproduction in any medium, provided you give appropriate credit to the original author(s) and the source, provide a link to the Creative Commons license, and indicate if changes were made.

\section{References}

1. Grewal, D., Motyka, S., Levy, M. (2018): The evolution and future of retailing and retailing education. J. Mark. Educ., 40, 85-93. https://doi.org/10.1177/ 0273475318755838.

2. Ivanov, S. (2019): Ultimate transformation: how will automation technologies disrupt the travel, tourism and hospitality industries? Z. Tourismuswiss., 11, 25-43. https://doi.org/10.1515/tw-2019-0003. 
3. Locsin, R. C., Ito, H. (2018): Can humanoid nurse robots replace human nurses? J. Nurs., 5, 1. https://doi.org/10.7243/2056-9157-5-1.

4. Appel, M., Marker, C., Mara, M. (2019): Otakuism and the appeal of sex robots. Front Psychol., 10, 569. https://doi.org/10.3389/fpsyg.2019.00569.

5. van Doorn, J., Martin, M., Noble, S. M., Hulland, J., Ostrom, A. L., Grewal, D., Petersen, J. W. (2017): Domo Arigato Mr. Roboto: emergence of automated social presence in organizational frontlines and customers' service experiences. J. Serv. Res., 20, 43-58. https://doi.org/10.1177/1094670516679272.

6. Robinson, H., MacDonald, B., Kerse, N., Broadbent, E. (2013): The psychosocial effects of a companion robot: a randomized controlled trial. J. Am. Med. Dir. Assoc., 14, 661667. https://doi.org/10.1016/j.jamda.2013.02.007.

7. Këpuiska, V., Bohouta, G. (2018): Next-generation of virtual personal assistants (Microsoft Cortana, Apple Siri, Amazon Alexa and Google Home). In Institute of Electrical and Electronics Engineers (Ed.), Proceedings of the 8th annual computing and communication workshop and conference, New York, NY: Curran Associates (pp. 99-103). https://doi.org/10.1109/CCWC.2018.8301638.

8. International Federation of Robotics, (2018): World robotics survey. Frankfurt, Germany: IFR. Retrieved from https://ifr.org [Accessed on 2019 August 12th].

9. Gnambs, T., Appel, M. (2019): Are robots becoming unpopular? Changes in attitudes towards autonomous robotic systems in Europe. Comput. Hum. Behav., 93, 53-61. https://doi.org/10.1016/j.chb.2018.11.045.

10. Graetz, G., Michaels, G. (2018): Robots at work. Rev. Econ. Stat., 100, 753-768. https://doi.org/10.1162/rest_a_00754.

11. Manyika, J., Lund, S., Chui, M., Bughin, J., Woetzel, J., Batra, P., Ko, R., Sanghvi, S. (2017): What the future of work will mean for jobs, skills, and wages. (McKinsey Global Institute report). [Accessed on 2019 August 12th]. Retrieved from: https://www.mckinsey.com/global-themes/future-of-organizations-and-work/whatthe-future-of-work-will-mean-for-jobs-skillsand-wages.
12. Smith, A., Anderson, M. (2017): Automation in everyday life. Washington, DC: Pew Research Center. [Accessed on 2019 August 12th.] Retrieved from: http://www. pewinternet.org/2017/10/04/automation-in-everyday-life/.

13. Commission, E., Parliament, E. (2017): Eurobarometer 87.1 (2017): TNS opinion [producer]. GESIS data archive, Cologne. ZA6861 data file version 1.2.0. Accessed on 2019 August 12th. https://doi.org/10.4232/1.12922.

14. Green, S. B. Yang, Y. (2009): Reliability of summed item scores using structura equation modeling: an alternative to coefficient alpha. Psychometrika, 74, 155-167. https://doi.org/10.1007/s11336-008-9099-3.

15. van Buuren, S. (2012): Flexible imputation of missing data. Boca Raton: CRC Press,

16. van Buuren, S., Groothuis-Oudshoorn, K. (2011): Mice: multivariate imputation by chained equations in R. J. Stat. Softw., 45, 1-67. https://doi.org/10.18637/ jss.v045.i03.

17. R Core Team (2019): R: a language and environment for statistical computing. Vienna, Austria: R Foundation for Statistical Computing. https://www.R-project.org/.

18. Albarracin, D., Shavitt, S. (2018): Attitudes and attitude change. Annu. Rev. Psychol, 69, 299-327. https://doi.org/10.1146/annurev-psych-122216-011911.

19. Venkatesh, V., Morris, M. G., Davis, G. B., Davis, F. D. (2003): User acceptance of information technology: toward a unified view. MIS Q., 27, 425-478. https://doi.org/ $10.2307 / 30036540$

20. Miller, N. E. (1944): Experimental studies of conflict. In J. M. Hunt (Ed.), Personality and the behavior disorders (pp. 431-465). Oxford: Ronald Pres.

21. Steenvoorden, E. H., van der Meer, T. W. (2017): Continent of pessimism or continent of realism? A multilevel study into the impact of macro-economic outcomes and political institutions on societal pessimism, European Union 2006-2012. Int. J. Comp. Sociol., 58, 192-214. https://doi.org/10.1177/0020715217710809.

22. Gnambs, T., Kaspar, K. (2015): Disclosure of sensitive behaviors across selfadministered survey modes: a meta-analysis. Behav. Res. Methods, 47, 1237-1259. https://doi.org/10.3758/s13428-014-0533-4

\section{Appendix: List of abbreviations}

\begin{tabular}{ll}
\hline Abbreviation & Description \\
\hline$N$ & Sample size \\
$M$ & Arithmetic mean \\
$S D$ & Standard deviation \\
$\omega$ & Omega reliability (see [14]) \\
$d$ & Standardized mean difference between groups \\
& $(M=0, S D=1)$ \\
$t$ & Test statistic of the $t$-distribution \\
$p$ & Degrees of freedom for $t$ \\
\hline
\end{tabular}

\section{Author}

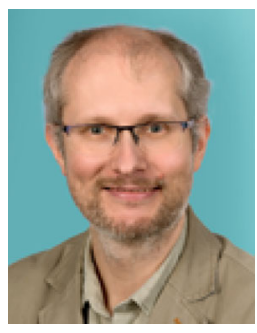

\section{Timo Gnambs}

Timo Gnambs studied psychology at the University of Vienna (2004), received his Ph.D. at the University of Nuremberg-Erlangen (2010), and his "Habilitation" at the Osnabruck University (2016). After finishing his postdoc at the Osnabruck University (Germany), he became head of the research unit Educational Measurement at the Leibniz Institute for Ed- ucational Trajectories in Bamberg (Germany). Since 2018 he is professor for psychology at the Johannes Kepler University Linz (Austria). His research focuses on longitudinal large-scale assessments, psychological and educational measurement, technology-based assessments, and media psychology. 